\title{
Effectiveness of a Targeted Occupational Health Intervention in Workers with High Risk of Sickness Absence: Baseline Characteristics and Adherence as Effect Modifying Factors in a Randomized Controlled Trial
}

\author{
Simo Taimela - Pasi Aronen - Antti Malmivaara • \\ Harri Sintonen · Jaakko Tiekso - Timo Aro
}

Published online: 11 December 2009

(C) The Author(s) 2009. This article is published with open access at Springerlink.com

\begin{abstract}
Introduction In a recently published randomized controlled trial (RCT), a targeted occupational health $(\mathrm{OH})$ intervention was found effective in an intentionto-treat analysis in controlling sickness absence among workers with high risk of sickness absence, compared to usual care. We performed an exploratory subgroup analysis in order to detect possible effect modifiers and mediators. Methods Age, gender, working status, severity of physical impairment, depression score, self-rated working ability, co-morbidity, and sickness absence characteristics in the previous 12 months were identified as potential effect modifiers $(n=382)$. We conducted regression analyses with the potential effect modifiers and a mediator (treatment
\end{abstract}

Trial Registration: ClinicalTrial.gov NCT00378989.

S. Taimela $(\bowtie) \cdot$ J. Tiekso

Evalua International, PO Box 35, 02661 Espoo, Finland

e-mail: simo.taimela@evalua.fi

J. Tiekso

e-mail: jaakko.tiekso@evalua.fi

P. Aronen $\cdot$ H. Sintonen

Department of Public Health, University of Helsinki,

Helsinki, Finland

e-mail: paaronen@mappi.helsinki.fi

H. Sintonen

e-mail: sintonen@mappi.helsinki.fi

\section{A. Malmivaara}

Centre for Health and Social Economics, National Institute for Health and Welfare, Helsinki, Finland

e-mail: antti.malmivaara@thl.fi

T. Aro

Mutual Pension Insurance Company Ilmarinen,

Helsinki, Finland

e-mail: timo.aro@ilmarinen.fi attendance as intended) as explanatory variables. The difference of sickness absence days during the previous year and the follow-up year was the dependent variable. Results The intervention was especially effective in the subgroups of workers who were certain that they will not be able to continue working in their current job due to health-related reasons ( -74 days; $95 \% \mathrm{CI}-105$ to -43 ), had co-morbidities ( -22.5 days; $95 \% \mathrm{CI}-35.5$ to -9.5 ), or severe physical impairment at work ( -17.5 days; $95 \% \mathrm{CI}-28.5$ to -6.5$)$. A modifying effect of age, gender, working status, depressive symptoms, or prior sickness absence on the effectiveness of this $\mathrm{OH}$ intervention was not found. Conclusions This targeted $\mathrm{OH}$ intervention seems especially suitable for workers who consider that they are no longer able to continue working due to health reasons and have high level of physical impairment or co-morbidities. The findings from these exploratory analyses should be tested in future RCTs.

Keywords Sickness absence - Subgroups · Effect modifier - Mediator - Occupational health intervention $\cdot$ Effectiveness

\section{Introduction}

Sickness absence, defined as non-attendance by an employee at work due to a health complaint, places a major economic burden on employers, the healthcare system, and the society as a whole. The optimal occupational health $(\mathrm{OH})$ intervention strategy for employees with high risk of sickness absence remains uncertain. In a recently published randomized controlled trial (RCT), a targeted $\mathrm{OH}$ intervention was found effective on controlling sickness absence among workers with high risk of sickness absence when compared 
to usual care at occupational health [1] and at the same time saving health care costs [2].

RCTs are considered the gold standard for assessing treatment effectiveness, but intention-to-treat analyses assess the average effect of treatments in the whole population sampled. Subgroups defined by baseline characteristics, i.e., modifiers of intervention response (who responds and who does not) can prompt researchers to target the intervention, and to seek better interventions for nonrespondents. Establishing mediators of intervention response (how an intervention works) can prompt researchers either to strengthen, add, or remove certain intervention components to make the intervention either more efficacious or more cost-effective [3]. Adherence to the suggested treatment or its components is a typical mediator of intervention.

Effectiveness classification by effect modifiers should be based on reliably measured and easily determined characteristics [4]. Furthermore, the effect modifiers should be relevant and plausible [4], and identifiable prior to analysis. In this study, information was gathered at baseline, before randomisation, on a number of factors that were considered potential effect modifiers for sick leave [5]. The following relevant and reliably measured potential effect modifiers were identified: age, gender, working status, sickness absence characteristics in the previous 12 months (register data), physical impairment at work, depression score, co-morbidities, and self-rated future working ability (questionnaire data). Adherence to the recommended treatment as intended was the mediator variable.

This paper describes the results of subgroup analyses, as applied to data from our RCT. Our study question was to explore which workers are most likely to benefit from the targeted $\mathrm{OH}$ intervention according to selected potential effect modifiers taking into account also a potential mediator of effect, i.e., adherence of the subjects to the intervention as intended.

\section{Methods}

Full details of the randomised controlled trial as intentionto-treat have been published previously $[1,2]$. In brief, the trial was conducted to compare the differences in sickness absence during the 12 month follow-up between the targeted $\mathrm{OH}$ intervention program and usual care for employees at high risk of sickness absence. The subjects came from one corporation in Finland. Forty-nine\% of them were employed in construction industry (civil engineering, building contracting, technical building services, and building materials industry). The remaining $51 \%$ were employed in repair, service and maintenance of buildings, industrial installations, or communications networks. The Helsinki University Research Ethics Board approved the study, and it was performed according to the Declaration of Helsinki.

At the beginning of the study health risk appraisals [5] were sent to a cohort of 3,115 employees with permanent employment and age between 18 and 60 years. The proposed study design, implications of the trial, and alternative options were explained in the cover letter. The letter also emphasised that taking part in the trial is voluntary, and employees will get the best treatment available and full attention of the occupational physician even if they do not want to participate. In addition, it was explained that participants are free to withdraw from the trial at any point, and it would not prejudice their treatment.

The eligible employees who had given their informed consent ( $n=1,341 ; 88 \%$ males; $62 \%$ blue-collar) were divided into three study groups 'Low Risk' $(n=386)$, 'Intermediate Risk' ( $n=537)$ and 'High Risk' $(n=418)$ of sickness absence on the basis of the health risk appraisal based on a priori defined interpretation cut-off limits. Subjects who reported problems with future working ability, pain, impairment due to musculoskeletal problems, insomnia or insufficient sleep, frequent stress or fatigue, or had a high depression score, were classified into the 'High Risk' group. Table 1 shows the items used and their cut-off limits for identifying the employees at high risk of sickness absence. Employees were included in the study regardless of their sickness absence status at the time of performing the health risk appraisal, but employees who had been granted a disability pension (part-time or full-time) were excluded.

Of the employees who met the trial eligibility criteria, 209 were randomised to the targeted $\mathrm{OH}$ intervention and 209 to control group receiving usual care at occupational health. 382 observations were eligible for the subgroup analyses.

\section{Interventions}

The employees in the targeted $\mathrm{OH}$ intervention group attended the occupational health program operated by their own occupational nurses and physicians. They received personal feedback of their survey results and an invitation to a consultation at their local occupational health service (OHS). The main purpose of the consultation was the construction of an action plan, and if appropriate, referral to a further consultation by a medical specialist or psychologist. The visits had a predefined content including the procedures how to further diagnose diseases and rules for further actions according to the process description. The occupational nurse wrote for each employee in the intervention group a personal file, which included information about the treatments and health advice received at the OHS, the referrals to further evaluation or interventions, the considerations of OHS professionals that no further 
Table 1 'High risk': findings in one or more of these topics

\begin{tabular}{ll}
\hline Topic & Criteria \\
\hline Physical impairment at work (0-10) [6] & Numerical rating scale $\geq 5$ \\
Pain & At least "moderate" pain that "affects working ability" at minimum three times a week \\
Self-rated future working ability [7] & Uncertain of own ability ("Uncertain"), or quite sure ("Not able") not being able \\
Depressive symptoms (0-30) [8] & DEPS score $\geq 11$ \\
Severe insomnia [9] & Problems in falling asleep or night awakenings AND daytime tiredness daily or almost daily \\
Work-related fatigue [10] & "Very much" feeling of being squeezed empty because of work \\
Work-related stress [6] & "Very much" feeling tense, strained, nervous and/or anxious because things are on one's \\
& mind all the time \\
\hline
\end{tabular}

actions were needed, and the refusals of some employees to take further action. Attendance (yes/no) in the consultation was used as the indicator variable "adherence as intended" in the present study. Altogether 142 (68\%) subjects participated in the $\mathrm{OH}$ intervention. Forty-eight occupational health centres were involved in the intervention program.

The employees in control group could consult their occupational nurse or physician on request, but they did not get feedback of their health survey results and were not invited for a consultation.

\section{Outcome measures}

Effectiveness was measured by the difference in the change in sickness absence days between the two treatment arms, i.e., the difference in sickness absence days between follow-up and prior year was calculated. Employee-specific sickness absence data, without medical diagnosis, were obtained from the employer's records, covering two consecutive periods from 1st October 2003 to 30th September 2004 (prior year) and from 1st October 2004 to 30th September 2005 (follow-up).

\section{Statistical methods}

Interaction tests are regarded as the most efficient tests to identify modifying factors for the effectiveness of treatment [11]. Analyses were carried out by using ordinary least squares (OLS) regression using both change scores and analysis of covariance (ANCOVA) methods. In the change score analysis we used the difference of sickness absence days during the year preceding the intervention and during the follow-up year as the dependent variable ("Gain Score"). This is a simple way to control relationship between two consecutive year measures [12]. For ANCOVA models sickness absence days during follow-up year was the dependent variable and sickness absence days during preceding year was included as a covariate.
Models were written in general form as GainScore ${ }_{i}=$ $\beta_{0}+\beta_{1} \times$ Intervention $_{1 i}+\beta_{2} \times$ Modifier $_{j i}+\beta_{3} \times$ (Intervention $_{1 i} \times$ Modifier $\left._{j i}\right)+\mu_{i}$, where $i=1, \ldots, 382$ and $j=\{$ Modifier1, Modifier2.... $\}$ for all the pre-specified effect modifiers and the mediator.

Treatment effect of intervention with modifier was calculated from the $\beta_{1} \times$ Intervention $_{1 i}+\beta_{3} \times$ (Intervention $_{1 i} \times$ Modifier $_{j i}$ ), where $\beta_{3}$ assess the variation caused by $j$ modifier, i.e., is the estimated modification effect.

All chosen modifiers were added to the model one by one. A level of significance of $P<0.10$ was considered to be relevant for modifiers [13]. Main results are reported treating modifiers as continuous variables when applicable. For mediator models the p-values were calculated from bootstrapped coefficients and standard errors [14].

For further illustrations we dichotomized continuous variables using cut-off limits that were based on our previous study in the same population concerning the determinants of sickness absence [5], or an arbitrary cut-off 14 days for prior sickness absence days (see Table 1). These results are presented as a forest plot, for which we included also the mediator variable where recorded participation in intervention was treated as acceptance-mediator (1: intervention group as intended to treat, 0 : not as intended to treat).

Sensitivity of the results was assessed by using informal Bayesian inference [15]. Here the idea is to assess the sensitivity of the base case results by generating random simulations from the normal distributions related to associated $\beta: s$ and the residual standard error $\sigma$ [12]. These results from the sensitivity analysis are reported only verbally. Statistical analyses were performed using SPSS 14.0 (SPSS Inc, Chicago, Illinois) and R 2.8.1 software.

\section{Results}

The mean difference between the treatment arms in the RCT as intention-to-treat was 11 days (95\% CI 1-20 days). 
Table 2 Definitions and the characteristics of the potential effect modifiers and mediator, and the results of the interaction tests with both change score (Gain Score) and ANCOVA analyses

\begin{tabular}{|c|c|c|c|c|}
\hline \multirow[t]{2}{*}{ Potential effect modifier } & \multicolumn{2}{|l|}{ Mean (SD) or $\%$} & \multicolumn{2}{|l|}{ Interaction } \\
\hline & Intervention group & Control group & Gain score $(P)$ & $\operatorname{ANCOVA}(P)$ \\
\hline Age & $49(9.4)$ & $50(9.5)$ & 0.87 & 0.95 \\
\hline Cut-off: $>39$ years & $76 \%$ & $76 \%$ & & \\
\hline Gender: female & $7 \%$ & $6 \%$ & 0.51 & 0.68 \\
\hline Occupational status: blue collar & $76 \%$ & $78 \%$ & 0.63 & 0.85 \\
\hline Sickness absence days in the previous 12 months & $6(32)$ & $4(35)$ & 0.47 & N/A \\
\hline Median (days) & 6 & 4 & & \\
\hline 75th percentile (days) & 20 & 18 & & \\
\hline Zero days & $34 \%$ & $43 \%$ & & \\
\hline Cut-off: $\geq 14$ days & $30 \%$ & $29 \%$ & & \\
\hline Physical impairment at work & $5(2.2)$ & $5(2.3)$ & 0.009 & 0.007 \\
\hline Cut-off: $\geq 5$ points & $62 \%$ & $68 \%$ & & \\
\hline Depression score & $4(5.3)$ & $5(5.2)$ & 0.15 & 0.36 \\
\hline Cut-off: $\geq 11$ points & $17 \%$ & $22 \%$ & & \\
\hline Self-rated future working ability: uncertain & $48 \%$ & $44 \%$ & 0.21 & 0.29 \\
\hline Self-rated future working ability: Not able & $8 \%$ & $9 \%$ & 0.00003 & 0.00002 \\
\hline Co-morbidity cut-off: $\geq 1$ & $44 \%$ & $51 \%$ & 0.01 & 0.02 \\
\hline Potential mediator & $\mathrm{N}(\%)$ & & & \\
\hline Attendance to the intervention as intended & $142(74 \%)$ & $192(100 \%)$ & 0.47 & 0.43 \\
\hline
\end{tabular}

N/A stands for not applicable

The bolded values denote significant interactions

The subgroup analyses resulted in significant interaction of the intervention with the factors of self-rated future working ability, severity of physical impairment, and comorbidity (Table 2). Modifying effects from age, gender, occupational status, depression score and sickness absence in previous 12 months were not statistically significant (Table 2). The attendance mediator was not significantly related to the outcome of the intervention.

The magnitudes of the moderating effects with the categorised factors can be seen from the forest plot (Fig. 1). The same inference holds for the acceptance mediator.

A modifying effect of self-rated future working ability was found: the intervention had a greater effect on employees who did not believe being able to continue at their present job due to health reasons ( -74 days; 95\% CI -105 to -43$)$ than for those who were uncertain about their future working ability ( -4.3 days; $95 \%$ CI -18.3 to 9.7) or those who believed in their own working ability ( -4.5 days; $95 \%$ CI -18.5 to 9.5 ).

Physical impairment at work modified the intervention effectiveness: the intervention had a greater effect on employees with high level of physical impairment $(-17.5$ days; $95 \%$ CI -28.5 to -6.5$)$ than for those with low level of impairment ( 2.5 days; $95 \%$ CI -13.5 to 18.5 ) with the cut-off limit $\geq 5$.
Reported co-morbidity was also an effect modifying factor: the intervention was more effective if employees had reported more than one health problem $(-22.5$ days; $95 \% \mathrm{CI}$ -35.5 to -9.5$)$ than without co-morbidities (1.5 days; $95 \%$ CI -11.5 to 14.5$)$.

In the informal Bayesian analyses severity of physical impairment, co-morbidity and self-rated future inability to work showed significant modifying effects. Also depression score and recorded prior sickness absence of over 14 days tended to have some modifying effects.

\section{Discussion}

These secondary analyses show that the targeted occupational health intervention was most effective in employees who did not believe being able to continue at their present job due to health-related reasons and had a high level of physical impairment or co-morbidities. With low levels of physical impairment the intervention was not more effective than usual care. The larger effect for those who did not believe in their own working ability is remarkable. Selfrated working ability strongly predicts sickness absence and permanent disability $[5,16]$. Thus, the occupational intervention seems especially suitable for improving 
Fig. 1 Forest plot indicating the estimated modification effects by factors; the difference of sickness absence days during the previous year and the follow-up year as the dependent variable ( $x$-axis). The vertical line indicates the effect of the intervention in intention-to-treat analyses

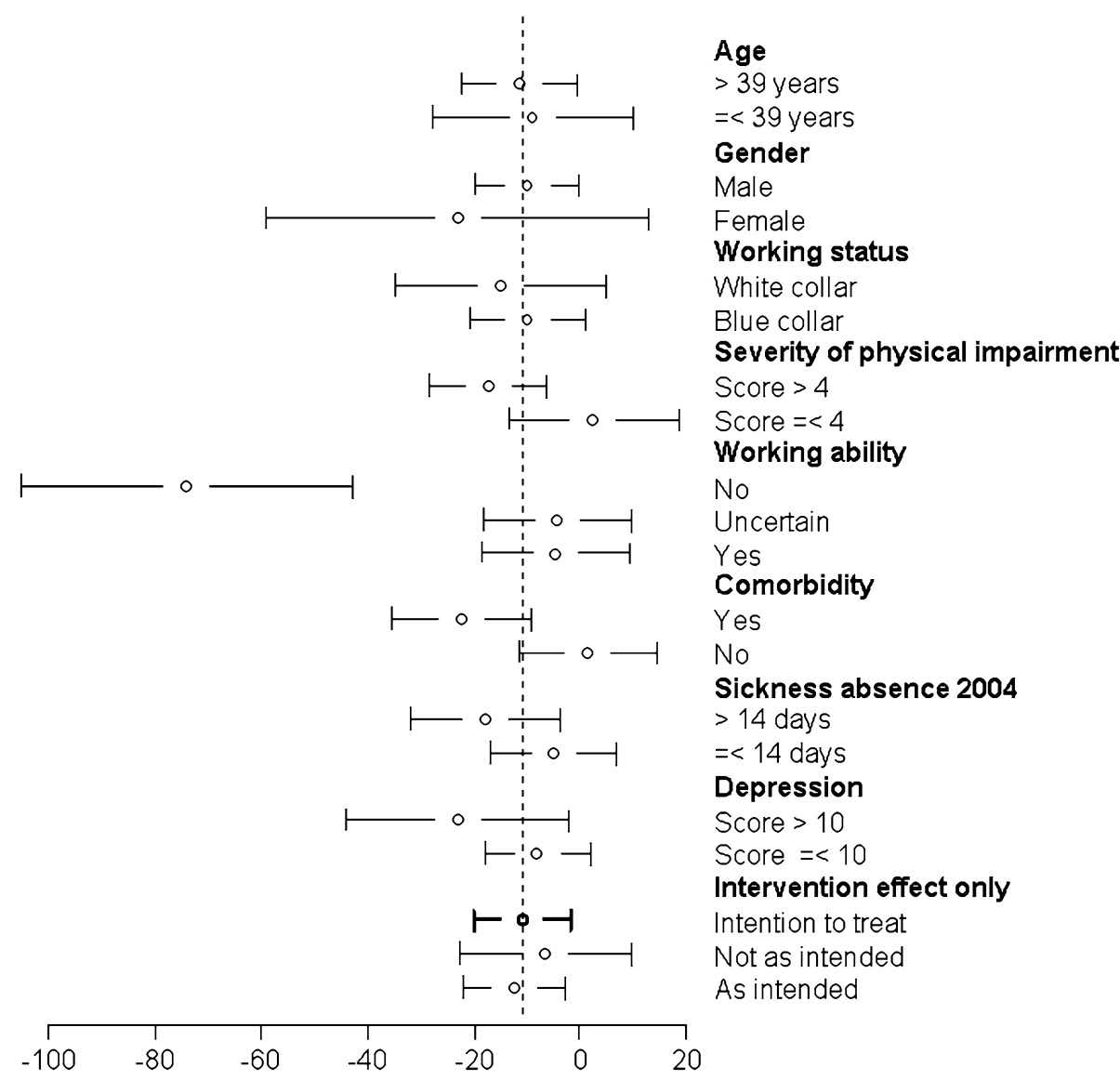

working ability of those workers that have musculoskeletal problems and doubt their own ability to continue working. Explanation for this phenomenon could be that many of those with severe musculoskeletal symptoms had been referred to an effective specialist care and their needs have been attended to. A positive effect for those that doubt their working ability does not, however, imply that the targeted occupational health intervention would be detrimental for the others.

Age, gender, depression score, occupational status and sickness absence at baseline did not appear to be modifiers for this intervention: the intervention was effective, no matter what the scores were on any of these scales.

From the forest plot we can see that the intervention effect is quite robust. Only self-rated future inability to work due to health reasons is a strong modifier. Informal Bayesian analysis (data not shown) gave almost similar inferences. In addition to co-morbidity, depression score and severity of physical impairment were found to have some modification effect in the sensitivity analyses.

Participation in intervention as intended did not show a significant mediating role. Those who had received an invitation to the OHS for consultation but did not attend may alternatively have sought help outside the OHS, e.g., through their own primary care physician. However, this finding could also be due to relatively small sample size. We also ran logistic regression analyses to find predictors for acceptance of intervention. None of the variables has statistically significant prediction power for that (data not shown).

Only few studies have attempted to determine possible effect modifiers of occupational health interventions, as even the number of RCTs is limited [17, 18]. Workers who perceived their disability to be moderate and workers with moderate scores for fear-avoidance beliefs return to work more rapidly as a result of the graded activity intervention for back pain than workers with higher scores [17]. Compared to the subgroups as determined in a trial for back pain based on a rather complex classification algorithm [19], our subgrouping of employees can be based on easily available baseline characteristics.

The present study is based on a RCT that provided a novel finding concerning the effectiveness and cost-effectiveness of the targeted occupational health intervention. The present analyses deepen our understanding on the underlying mechanisms of the effectiveness, clarifying the role of both effect modifiers and the mediating effect of adherence to the intervention. However, these analyses must be regarded as exploratory because the sample size does not provide sufficient statistical power to examine 
fully modifier- or mediator-defined subgroups, and because of the repeated statistical testing. The fact that the study is somewhat underpowered as regards these subgroup analyses can e.g. be seen from the forest plot where only one dichotomised effect modifier was found significant. Although the sample size of the original RCT was 418 at baseline, for the present analyses 382 observations were eligible. Nevertheless the results will generate hypotheses and should be tested formally in future RCTs.

The change score analysis and ANCOVA are commonly used statistical tools for pre and post test analyses. ANCOVA is often preferred over a change score analysis $[20,21]$. The gain score estimator with two periods and two comparison groups setting is valid only if the assumption that changes in the estimator over time would have been exactly the same in both groups in the absence of intervention. This seems to be largely true as the two intervention arms were rather identical at baseline of the study [1]. Nevertheless, we chose to report the interaction analysis results from both, but the Forest plot only with the gain score results because the results from the change score analysis are much easier to interpret. In the present study the change score analysis primarily answers to the study question of whether the average change of sickness absence days is the same between the subgroups, i.e., is there a treatment effect with important modifiers or mediator. With ANCOVA the study question is whether there is a treatment effect with important modifiers or mediator, which is not predictable from the previous year sickness absence days. Nevertheless the gain score analysis and ANCOVA pointed out the same effect modifiers, so the selection of the method of analysis did not affect the interpretation of our results.

The findings from our exploratory analyses should be formally tested in future RCTs. Future trials should consider moderating effects a priori and should collect the appropriate data accordingly. Not only should data be collected to adjust for unequal distribution of well known prognostic factors between the intervention groups, but also data on potential modifying factors or clusters of modifying factors in order to create hypotheses for further trials. As adherence is usually of importance in interventions relying on human behaviour, we suggest that also the effect mediators would be taken into account. Based on the accumulating results from trials in occupational health research, new approaches can be developed to get the most (cost-)effective interventions for specific groups of patients in the future.

\section{Conclusions}

The targeted occupational health intervention is more effective for workers who consider that they are no longer able to continue working due to health-related reasons and have high level of physical impairment or co-morbidities. A modifying effect of age, gender, occupational status, depressive symptoms or prior sickness absence on the effectiveness of this intervention was not found. The findings from these exploratory analyses should, however, be tested in future RCTs. In future studies in the occupational health setting not only should data be collected to adjust for unequal distribution of well known prognostic factors between the intervention groups, but also data on potential modifying factors or clusters of moderating factors.

Competing interests ST and JT are shareholders of Evalua International that provided the health risk appraisal that was used in the study. PA, AM, HS and TA have no competing interests to declare. Funding for the study was provided by The Finnish Funding Agency for Technology and Innovation (TEKES), The Finnish National Fund for Research and Development (SITRA), and Pfizer Oy. The authors' work was independent of the funders.

Open Access This article is distributed under the terms of the Creative Commons Attribution Noncommercial License which permits any noncommercial use, distribution, and reproduction in any medium, provided the original author(s) and source are credited.

\section{References}

1. Taimela S, Malmivaara A, Justen S, Läärä E, Sintonen H, Tiekso $\mathrm{J}$, et al. The effectiveness of two occupational health intervention programmes in reducing sickness absence among employees at risk. Two randomised controlled trials. Occup Environ Med. 2008;65:236-41.

2. Taimela $S$, Justen $S$, Aronen $P$, Sintonen $H$, Läärä E, Malmivaara A, et al. An occupational health intervention programme for workers at high risk for sickness absence. Cost effectiveness analysis based on a randomised controlled trial. Occup Environ Med. 2008;65:242-8.

3. Kraemer HC, Frank E, Kupfer DJ. Moderators of treatment outcomes: clinical, research, and policy importance. JAMA. 2006; 296:1286-9.

4. Laupacis A, Sekar N, Stiell IG. Clinical prediction rules. A review and suggested modifications of methodological standards. JAMA. 1997;277:488-94.

5. Taimela S, Läärä E, Malmivaara A, Tiekso J, Sintonen H, Justen $\mathrm{S}$, et al. Self-reported health problems and sickness absence in different age groups predominantly engaged in physical work. Occup Environ Med. 2007;64:739-46.

6. Implementation and methods of the Health 2000 Survey. Menetelmäraportti. Terveys 2000-tutkimuksen toteutus, aineisto ja menetelmät. Helsinki: National Public Health Institute; 2005.

7. Tuomi K, Ilmarinen J, Jahkola A, Katajarinne L, Tulkki A. Work ability index (Työkykyindeksi). Helsinki: Finnish Institute of Occupational Health; 1992.

8. Salokangas RK, Poutanen O, Stengard E. Screening for depression in primary care. Development and validation of the Depression Scale, a screening instrument for depression. Acta Psychiatr Scand. 1995;92:10-6.

9. Partinen M, Gislason T. Basic Nordic Sleep Questionnaire (BNSQ): a quantitated measure of subjective sleep complaints. J Sleep Res. 1995;4:150-5. 
10. Kauppinen T, Hanhela R, Heikkilä P, Lehtinen S, Lindström K, Toikkanen J, et al. Work and health in Finland in 2003 (Työ ja terveys Suomessa 2003). Helsinki: Finnish Institute of Occupational Health; 2003.

11. Pocock SJ, Assmann SE, Enos LE, Kasten LE. Subgroup analysis, covariate adjustment and baseline comparisons in clinical trial reporting: current practice and problems. Stat Med. 2002;21: 2917-30.

12. Gelman A, Hill J. Data analysis using regression and multilevel/ hierarchial models. New York: Cambridge University Press; 2007.

13. Collett D. Modelling survival data in medical research. London: Chapman \& Hall; 1994

14. Preacher KJ, Hayes AF. Asymptotic and resampling strategies for assessing and comparing indirect effects in multiple mediator models. Behav Res Methods. 2008;40:879-91.

15. Wijeysundera DN, Austin PC, Hux JE, Beattie WS, Laupacis A. Bayesian statistical inference enhances the interpretation of contemporary randomized controlled trials. J Clin Epidemiol. 2009;62:13-21. e5.
16. Josephson M, Heijbel B, Voss M, Alfredsson L, Vingard E. Influence of self-reported work conditions and health on full, partial and no return to work after long-term sickness absence. Scand J Work Environ Health. 2008;34:430-7.

17. Staal JB, Hlobil H, Koke AJ, Twisk JW, Smid T, van Mechelen W. Graded activity for workers with low back pain: who benefits most and how does it work? Arthritis Rheum. 2008;59:642-9.

18. Nystuen P, Hagen KB. Solution-focused intervention for sick listed employees with psychological problems or muscle skeletal pain: a randomised controlled trial [ISRCTN39140363]. BMC Public Health. 2006;6:69.

19. Brennan GP, Fritz JM, Hunter SJ, Thackeray A, Delitto A, Erhard RE. Identifying subgroups of patients with acute/subacute "nonspecific" low back pain: results of a randomized clinical trial. Spine. 2006;31:623-31.

20. Senn S. Change from baseline and analysis of covariance revisited. Stat Med. 2006;25:4334-44.

21. Twisk J, Proper K. Evaluation of the results of a randomized controlled trial: how to define changes between baseline and follow-up. J Clin Epidemiol. 2004;57:223-8. 